\title{
Introduction of "Sugar Tax" in South Africa: Placebo or panacea to curb the onset of cardio-metabolic diseases?
}

Janina Benade and M. Faadiel Essop

Cardio-Metabolic Research Group (CMRG),

Department of Physiological Sciences, Stellenbosch University, Stellenbosch, South Africa.

Address for correspondence:

Prof M. Faadiel Essop

Cardio-Metabolic Research Group (CMRG)

Department of Physiological Sciences

Stellenbosch University

Room 2009, Mike De Vries Building

Merriman Avenue

Stellenbosch

7600

South Africa

Email:

mfessop@sun.ac.za

The South African Minister of Finance noted in his 2016 budget speech that a 20\% "sugar tax" would be introduced during 2017. This has since raised considerable debate with proponents welcoming the announcement as a measure to counter obesity-related diseases, while the beverage industry responded that it would come at significant costs to the South African economy. In light of such diverse views it is useful to reflect on the key question that emerges, i.e. would such a tax be an effective strategy to counter the effects of higher sugar intake if the latter is indeed the cause of increased disease onset? The intake of added sugars by South Africans has substantially increased over the last few decades. ${ }^{(1)}$ This forms part of the so-called nutrition transition in especially developing countries where distinct changes in dietary patterns and nutrient intake occur with economic development and urbanisation. (2) Dietary sugars are derived from a range of foodstuffs, but sugar-sweetened beverages (SSBs) that include sodas, fruit juices, energy drinks and sweetened milk drinks provide a significant proportion of added sugars. ${ }^{(1,3)}$ This perspective article will briefly consider trends in SSB consumption, its association with the onset of obesity, diabetes and heart diseases and the potential of a "sugar tax" to curb the pandemic of cardio-metabolic diseases.

\section{ABSTRACT}

During 2016 an announcement was made that South Africans will be obliged to pay a $20 \%$ "sugar tax" that will soon be implemented in order to help curb the rising prevalence of cardio-metabolic diseases. This announcement was met with mixed responses, with strong support from some quarters while others questioned whether it would indeed lead to improved health and well-being of South Africans. As sugarsweetened beverages (SSBs) constitute a significant portion of added sugars in modern-day diets, it is firmly in the cross-hairs of the new taxation. This perspective article reflects on the proposed sugar tax by exploring the nature of SSB consumption patterns, evaluating epidemiological evidence associating SSB intake to cardio-metabolic diseases risk and by considering examples where a similar tax had previously been introduced. Here data reveal that there is robust evidence supporting a detrimental link between high SSB consumption patterns and the onset of cardiometabolic diseases. It is therefore our strong opinion that the sugar tax option should be pursued in parallel with well-designed, long-term studies to evaluate whether it decreases SSB intake and lowers the prevalence of cardio-metabolic diseases within the South African context. SAHeart 20 17;14:148-153

The first SSB was produced and consumed in the 1800 s, but only gained popularity during World War II when free Coca Cola ${ }^{\mathrm{TM}}$ products were donated to the US army. The consumption of all SSB types including carbonated, sports, fruit drinks and vitamin waters increased significantly between 1970 and 2000. In recent years the sales and consumption of SSBs have increased rapidly in non-Western and low- and middle income countries in particular. For example, in China the trading of Coca Cola ${ }^{\mathrm{TM}}$ and PepsiCo ${ }^{\mathrm{TM}}$ products rose by $145 \%$ and 127\%, respectively, between 2000 and 20I0.(4) In Mexico, SSB sales increased in a similar fashion between 1999 and $2012,{ }^{(5)}$ while annual sales in South Africa is also increasing. ${ }^{(6)}$ This is possibly due to the fact that SSBs have became increasingly affordable, especially in low- and middle-income countries over the past decade. (7) The WHO makes a strong recommendation that the consumption of free sugars should strictly be kept below 10\% of the total calorie intake, but that a limit of $5 \%$ could have added health benefits. The British Scientific Advisory Committee on Nutrition and American Heart Association made similar, or stricter, recommenda- 
tions. ${ }^{(8)}$ To put this into perspective, one $330 \mathrm{ml}$ can of soda contains $\sim 7$ - 9 teaspoons of sugar, i.e. a single serving already surpasses the daily recommendation.

Despite such recommendations, the role of SSB consumption in terms of disease onset remains controversial. ${ }^{(9)}$ It is important to bear in mind that SSB intake can promote cardiometabolic diseases onset through direct or indirect mechanisms. As SSBs are energy dense, their consumption is associated with excessive caloric intake and subsequent weight gain that may, in turn, result in the development of cardio-metabolic complications. However, increased SSB consumption may also elicit direct metabolic effects that occur independently of body weight and energy balance.

This section will explore the link between SSB consumption and cardio-metabolic diseases. Although a vast number of studies were considered in the writing of this section, only studies published after I January 2013 will be cited here. There are ample large-scale $(n>40$ 000) long-term (follow-up >5 years) epidemiological studies published during the early 2000 s that provide considerable evidence to prove the positive

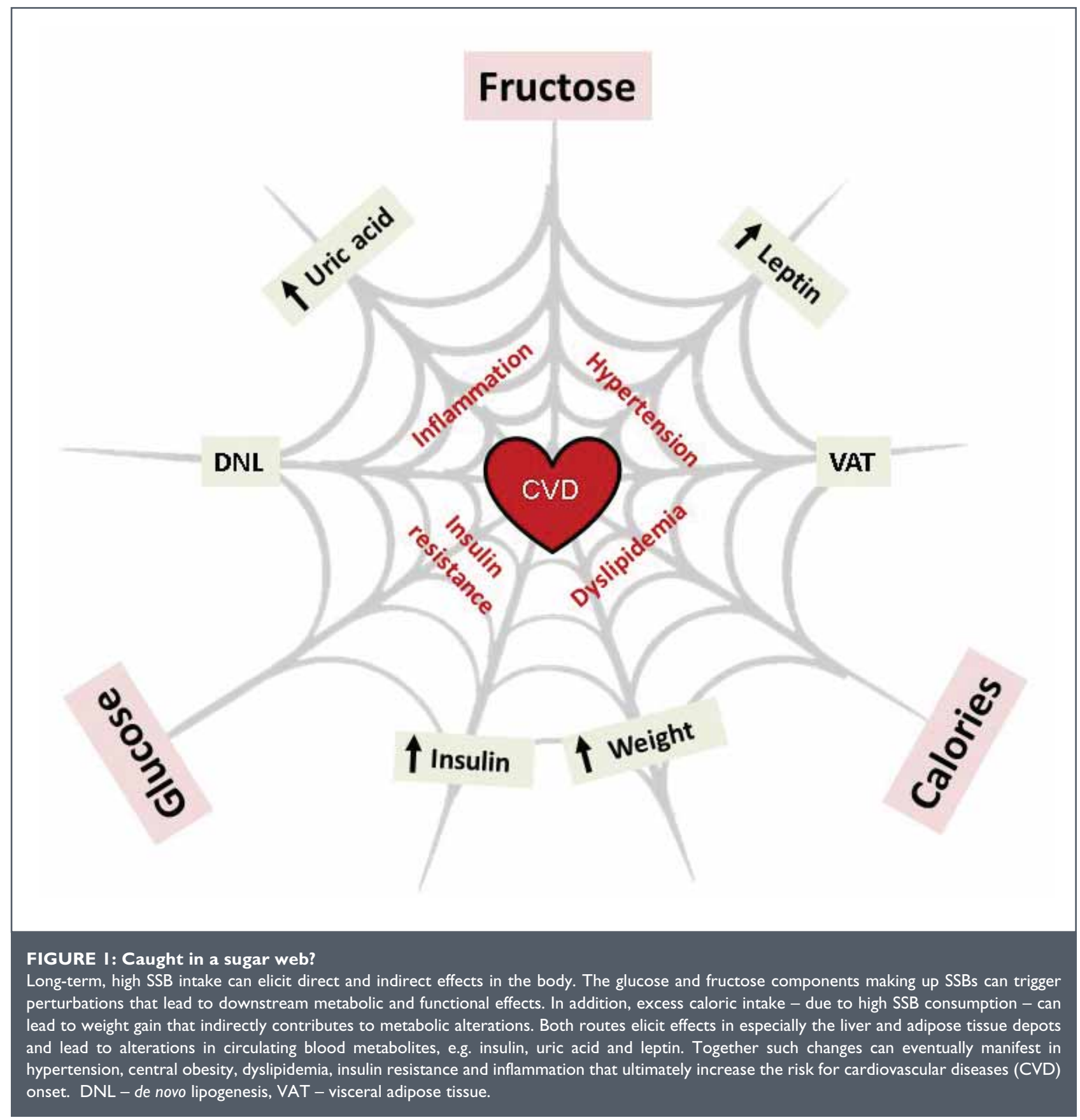


association between SSBs and weight gain and the eventual risk of developing obesity. Earlier observational data further show that a decrease in SSB intake can lead to significant weight loss. Epidemiological studies from across the globe also show that children and adolescents are especially vulnerable to weight gain due to SSB consumption. ${ }^{(10-13)}$ Extensive reviews and metaanalyses have also been generated on the link between SSB consumption and weight gain and the bulk of these supports the direct association between SSB consumption and obesity, including the most recent meta-analysis. ${ }^{(14)}$

SSB consumption can also, directly or indirectly, promote the onset of hypertension, ${ }^{(15-18)}$ dyslipidemia, ${ }^{(18,19)}$ and impaired glucose tolerance (Figure I).(20) Evidence from these studies suggests that the effects of SSB consumption occur partly through direct and indirect (increased calorie intake and weight gain) mechanisms (refer to Table I). The concurrent manifestation of such metabolic conditions is known as the metabolic syndrome (MetS) that serves as a prognostic tool to predict the future development of Type 2 Diabetes Mellitus (T2DM) and cardiovascular diseases (CVD). ${ }^{(21)}$ Considering the strong association between SSB intake and the MetS, it is interesting to consider the evidence regarding SSB intake and T2DM and CVD risk.
Accordingly, we identified longitudinal studies that explored the association between SSB intake and T2DM.(22-26) All but one of these studies found that frequent SSB consumption significantly increased the risk of developing T2DM in a dosedependent manner. Two recent meta-analyses concurred that every additional daily SSB serving relates to a $\sim 18-20 \%$ increase in the risk of developing T2DM. ${ }^{(27,28)}$ There are less data available regarding the direct relationship between SSB consumption and CVD onset but there is some recent evidence that it may lead to a higher incidence of myocardial infarction, ${ }^{(29)}$ stroke, ${ }^{(29)}$ heart failure ${ }^{(30)}$ and CVD mortality. ${ }^{(31,32)}$

By introducing a "sugar tax", South Africa is following in the footsteps of France, Mexico, the United Kingdom and some cities in the United States. The WHO recently endorsed the use of a sugar tax as a strategy to reduce SSB consumption and obesity. Moreover, researchers from across the globe are advocating the potential benefits of SSB taxing. ${ }^{(33-35)}$ In South Africa researchers estimate that a $20 \%$ tax would lower the prevalence of obesity by $2.4 \%$ in females and $3.8 \%$ in males, that should result in 220000 less obese adults in South Africa. ${ }^{(36)}$ In addition, it is estimated that the incidence of stroke over the next 20 years will be reduced by $85000 .{ }^{(37)}$ It is,

\section{TABLE I: The direct and indirect effects of SSB consumption.}

\begin{tabular}{|c|c|c|}
\hline Author & Evidence of indirect effect of SSBs & Evidence of direct effect of SSBs \\
\hline Kosova, et al. ${ }^{(18)}$ & $\begin{array}{l}\text { The influence of SSB intake on total calorie intake and } \\
\text { unadjusted BMI is not reported. }\end{array}$ & $\begin{array}{l}\text { Multivariate linear regression adjusting for energy intake } \\
\text { and other factors show a positive association between SSB } \\
\text { intake and components of the MetS. }\end{array}$ \\
\hline Loh, et al. ${ }^{(20)}$ & $\begin{array}{l}\text { The frequency of SSB consumption did not have a } \\
\text { significant effect on BMI. }\end{array}$ & $\begin{array}{l}\text { Multivariate analyses showed that the significant association } \\
\text { between SSB intake and all metabolic parameters persisted } \\
\text { after the adjustment for BMI and dietary patterns. }\end{array}$ \\
\hline Bhupathiraju, et al.(22) & Higher SSB intake was associated with increased BMI. & $\begin{array}{l}\text { SSB intake is significantly associated with increased risk of } \\
\text { developing T2DM after adjusting for BMI, total calorie } \\
\text { intake and other factors. }\end{array}$ \\
\hline Fagherazzi, et al..(23) & $\begin{array}{l}\text { The influence of SSB intake on total calorie intake and } \\
\text { unadjusted BMI is not reported. }\end{array}$ & $\begin{array}{l}\text { The significant association between SSB intake and T2DM } \\
\text { persisted after the adjustment for BMI, total calorie intake } \\
\text { and other factors. }\end{array}$ \\
\hline Sakurai, et al.(24) & $\begin{array}{l}\text { The frequency of SSB intake was positively associated with } \\
\text { BMI and total calorie intake. }\end{array}$ & $\begin{array}{l}\text { After controlling for BMI, total calorie intake and other } \\
\text { factors the hazard ratio for developing T2DM as a result of } \\
\text { SSB intake was no longer significant. }\end{array}$ \\
\hline Teshima, et al.(25) & $\begin{array}{l}\text { The influence of SSB intake on total calorie intake and } \\
\text { unadjusted BMI is not reported. }\end{array}$ & $\begin{array}{l}\text { The logistic analysis did not consider BMI, weight or total } \\
\text { calorie intake. }\end{array}$ \\
\hline The Interact consortium (26) & $\begin{array}{l}\text { The frequency of SSB consumption is associated with } \\
\text { higher calorie intake. }\end{array}$ & $\begin{array}{l}\text { Multivariate analyses showed that the significant association } \\
\text { between SSB intake and T2DM persisted after the } \\
\text { adjustment for BMI, total calorie intake and other factors. }\end{array}$ \\
\hline Rahman, et al. (30) & $\begin{array}{l}\text { The influence of SSB intake on total calorie intake and } \\
\text { unadjusted BMI is not reported. }\end{array}$ & $\begin{array}{l}\text { Multivariate analyses showed that the significant association } \\
\text { between SSB intake and heart failure in males persisted } \\
\text { after the adjustment for BMI, total calorie intake and other } \\
\text { factors. }\end{array}$ \\
\hline Yang, et al. ${ }^{(31)}$ & $\begin{array}{l}\text { The influence of SSB intake on total calorie intake and } \\
\text { unadjusted BMI is not reported. }\end{array}$ & $\begin{array}{l}\text { Sugar consumption is significantly associated with } \\
\text { cardiovascular mortality after the adjustments were made } \\
\text { for BMI, total calorie intake and other factors. }\end{array}$ \\
\hline Micha, et al. ${ }^{(32)}$ & $\begin{array}{l}\text { The influence of SSB intake on total calorie intake and } \\
\text { unadjusted BMI is not reported. }\end{array}$ & $\begin{array}{l}\text { This analysis did not did not consider the role of BMI, } \\
\text { weight or total calorie intake. }\end{array}$ \\
\hline
\end{tabular}


however, important to remember that such projections are based on certain assumptions. ${ }^{(34)}$ For example, the assumption is made that a 10\% tax will result in a corresponding 10\% increase in the retail price, i.e. that retailers and manufacturers will not absorb the cost of the added tax. ${ }^{(38)}$ It is a useful exercise to consider how taxation has actually impacted on SSB sales and consumption in countries where such measures have been adopted. For example, in Berkley (California) a penny per fluid ounce ( $\mid \not / o z$.) taxation on beverages with added caloric sweeteners was approved at the end of 2014.(39) Here they found that $>100 \%$ of the SSB tax was passed on to consumers by gas stations and grocery chain stores, but less so by pharmacies and independent corner shops or gas stations. Overall, there was a 67\% "pass-through" of tax. There are also questions regarding the potential of a price increase to induce a sustained decrease in SSB intake and whether the food industry will attempt to counter this, e.g. by employing more aggressive marketing strategies. ${ }^{(38,40)}$ Here Mexico is a valuable example to consider as they implemented a I peso-per-liter SSB tax in January 2014 in an attempt to curb the high prevalence of overweight, obesity and diabetes. Early data indicated that there was an average decrease of $6 \%$ in sales during the first year after the tax implementation. ${ }^{(40)}$ A follow-up study showed that the decrease in SSB sales was not only sustained, but declined even further during the second year after the tax implementation. ${ }^{(41)}$ A final concern regarding the projections above is that it makes assumptions regarding the extent to which SSB-derived calories will be replaced by the consumption of alternative (untaxed) food or beverages. Although this does not exclude the possibility that SSBs might be replaced with other unhealthy dietary options, the decrease in SSB sales was accompanied by a substantial increase in the purchase of bottled water in Berkeley and Mexico, respectively. ${ }^{(39,42,43)}$

Despite all the evidence that supports the notion that a sugar tax has the potential to bring a significant and sustained reduction in SSB consumption, there is not agreement that it would be the correct strategy for South Africa. The Beverage Society of South Africa also projects that the introduction of a sugar tax will lead to the loss of around 60000 jobs in the beverage industry and also cut their contribution to the South African GDP by approximately RI4 billion. ${ }^{(44)}$ However, the National Treasury has opposed this argument, claiming the job losses as a result of the sugar tax will be 5000 , at most. ${ }^{(45)}$ Additionally it was argued that the significant economic burden of noncommunicable diseases should also be taken into account. Although the net effect of the sugar tax on the South African economy remains to be seen, there may be reason for concern. Denmark repealed its long-standing SSB tax in 2014 after deeming it ineffective and detrimental to the economy. ${ }^{(46)}$
Berkeley, on the other hand, observed a substantial increase in tax revenue without a significant decrease in store revenue per purchase (compared to non-Berkeley stores). ${ }^{(39)}$

To conclude, there is robust evidence that high SSB consumption contributes to the onset of cardio-metabolic diseases. Early data from Mexico and Berkeley suggest that a sugar tax may be an effective strategy to reduce SSB intake and counter the rising prevalence of non-communicable diseases. In light of all the evidence here reviewed, it is our strong recommendation that it is worth pursuing the "sugar tax" option in South Africa as part of a multi-pronged strategy to reduce SSB consumption and curb the onset of cardio-metabolic diseases. It is, however, clear that the potential benefits (or detrimental outcomes) of a sugar tax within the South African context is not entirely predictable yet. Thus additional well-designed, long-term studies are required to determine the true impact of such a tax in South Africa. Such a study should include a large, representative sample and complete data sets on beverage sales and consumption over a long pre-tax period. In addition, it would be important to determine other changes in dietary patterns that are encouraged, or discouraged, by the sugar tax, e.g. increased consumption of artificially sweetened beverages. The impact on unemployment and gross domestic product should also be evaluated and compared against the projected savings that should accrue due to improved public health and well-being.

\section{Conflict of interest: none declared.}




\section{REFERENCES}

1. Temple NJ, Steyn NP. Sugar and health: A food-based dietary guideline for South Africa. South African J Clin Nutr 2013;26(3): 100-4.

2. Popkin B, Adair L, Ng S. Now and then: The global nutrition transition: The pandemic of obesity in developing countries. Nutr Rev 20 12;70(1):3-21.

3. Maunder EMW, Nel JH, Steyn NP, Kruger HS, Labadarios D. Added sugar, macro- and micronutrient intakes and anthropometry of children in a developing world context. PLoS One (Internet) 20I5; I0(I I): I-24. Available from: http://dx.doi.org/ | 0.137|/journal.pone.0142059.

4. Kleiman S, Ng SW, Popkin B. Drinking to our health: Can beverage companies cut calories while maintaining profits? Obes Rev 20 | 2; 13:258-74.

5. Stern D, Piernas C, Barquera S, Rivera JA, Popkin BM. Caloric beverages were major sources of energy among children and adults in Mexico, 1999. 2012. J Nutr 20 I 4; 144:949-56

6. Tugendhaft A, Manyema M, Veerman LJ, Chola L, Labadarios D, Hofman KJ. Cost of inaction on sugar-sweetened beverage consumption: Implications for obesity in South Africa. Public Health Nutr (Internet) 2015;19(13): 1-9. Availablefrom:http://www.journals.cambridge.org/abstract_SI 3689800 I 5003006.

7. Blecher E, Liber A, Drope J, Nguyen B, Stoklosa M. Global Trends in the Affordability of Sugar-Sweetened Beverages, 1990-2016. Prev Chronic Dis.20 17; 4: | 60406. DOI: http://dx.doi.org/| 0.5888/pcd I 4. 160406.

8. Rippe JM, Sievenpiper JL, Lê K-A, White JS, Clemens R, Angelopoulos TJ. What is the appropriate upper limit for added sugars consumption? Nutr Rev 2016;75(1):18-36

9. Stanhope KL. Sugar consumption, metabolic disease and obesity: The state of the controversy. Crit Rev Clin Lab Sci 2016;53(I):52-67.

10. Beck AL, Tschann J, Butte NF, Penilla C, Greenspan LC. Association of beverage consumption with obesity in Mexican American children. Public Health Nutr 20 14;17(2):338-44.

II. DeBoer MD, Scharf RJ, Demmer RT. Sugar-sweetened beverages and weight gain in 2- to 5-year-old children. Paediatrics 2013;132(3):413-20.

12. Grimes CA, Riddell LJ, Campbell KJ, Nowson CA. Dietary salt intake, sugar-sweetened beverage consumption, and obesity risk. Paediatrics 2013;131:|4-21.

13. Dubois L, Farmer A, Girard M, Peterson K. Regular sugar-sweetened beverage consumption between meals increase risk of overweight among preschool-aged children. J Am Diet Assoc 2007; 107:924-34.

14. Ruanpeng D, Thongprayoon C, Cheungpasitporn W, Harindhanavudhi T. Sugar and artificially sweetened beverages linked to obesity: A systematic review and meta-analysis. QJM An Int J Med (Internet) 2017;5 I 4(February): 18|-6. Available from: https://academic.oup.com/qjmed/article-lookup/doi/ 10.1093/gjmed/hcx068

15. Xi B, Huang $Y$, Reilly $\mathrm{KH}$, et al. Sugar-sweetened beverages and risk of hypertension and CVD: A dose - response meta-analysis. Br J Nutr (Internet) 2015;1|3(5):709-17. Available from: http://www.journals.cambridge.org/ abstract_S0007||45| 4004383.

16. Jayalath $\mathrm{VH}, \mathrm{D}$ Souza RJ, Ha V, et al. Sugar-sweetened beverage consumption and incident hypertension: A systematic review and meta-analysis of prospective cohorts I - 3. Am J Clin Nutr 2015; |02:9|4-21.

17. Kim Y, Je Y. Prospective association of sugar-sweetened and artificially sweetened beverage intake with risk of hypertension. Arch Cardiovasc Dis 2016;109(4):242-53.

18. Kosova $\mathrm{E}$, Auinger $\mathrm{P}$, Bremer $\mathrm{A}$. The relationships between sugar-sweetened beverage intake and cardiometabolic markers in young children. J Acad Nutr Diet 2013;1।3(2):219-27.

19. Stanhope KL, Medici V, Bremer AA, et al. A dose-response study of consuming high-fructose corn syrup-sweetened beverages on lipid/lipoprotein risk factors for cardiovascular disease in young adults. Am J Clin Nutr 20I5; 10।(6):1144-54
20. Loh D, Moy F, Zaharan N, Jalaludin M, Mohamed Z. Sugar-sweetened beverage intake and its associations with cardiometabolic risks among adolescents. Paediatr Obes 2017;12(1):el-5.

21. Alberti K, Eckel RH, Grundy SM. Harmonising the metabolic syndrome. Circulation 2009; 120:1640-5.

22. Bhupathiraju SN, Pan A, Malik VS. Caffeinated and caffeine-free beverages and risk of type 2 diabetes. Am J Clin Nutr 2013;97:155-6.

23. Fagherazzi G, Vilier A, Sartorelli DS, Lajous M, Balkau B, Clavel-Chapelon F. Consumption of artificially and sugar-sweetened beverages and incident type 2 diabetes in the Etude Epidmiologique auprs des femmes de la Mutuelle Generale de l'Education Nationale European Prospective Investigation into cancer and nutrition cohort. Am J Clin Nutr 20 I 3;97(3):5 I 7-23.

24. Sakurai M, Nakamura K, Miura K, et al. Sugar-sweetened beverage and diet soda consumption and the 7-year risk for type 2 diabetes mellitus in middleaged Japanese men. Eur J Nutr 20 14;53:25।-8.

25. Teshima N, Shimo M, Miyazawa K, et al. Effects of sugar-sweetened beverage intake on the development of type 2 diabetes mellitus in subjects with impaired glucose tolerance: The Mihama Diabetes Prevention Study. J Nutr Sci Vitaminol 2015;61:14-19.

26. Consortium TI. Consumption of sweet beverages and type 2 diabetes incidence in European adults: Results from EPIC-InterAct. Diabetologia 2013;56:1520-30

27. Greenwood DC, Threaplton DE, Evans CEL, et al. Association between sugar-sweetened and artificially sweetened soft drinks and type 2 diabetes: Systematic review and dose-response meta- analysis of prospective studies. Br J Nutr 20 | 4; I 12:725-34

28. Imamura $\mathrm{F}, \mathrm{O}^{\prime}$ Connor L, Ye Z, et al. Consumption of sugar sweetened beverages, artificially sweetened beverages, and fruit juice and incidence of type 2 diabetes: Systematic review, meta-analysis, and estimation of population attributable fraction. BMJ 20 I5;35 I (h3576).

29. Narain A, Kwok C, Mamas M. Soft drink intake and the risk of metabolic syndrome: A systematic review and meta-analysis. Int J Clin Pract 2017;71:el2927. https://doi.org/10.1 I I I/ijcp. 12927.

30. Rahman I, Wolk A, Larsson SC. The relationship between sweetened beverage consumption and risk of heart failure in men. Heart 2015; (101):1961-5.

31. Yang Q, Zhang Z, Gregg EW, Flanders WD, Merritt R, Hu FB. Added sugar intake and cardiovascular diseases mortality among US adults. JAMA Intern Med (Internet) 2014;174(4):5 I6-24. Available from: http://archinte. jamanetwork.com/article.aspx?articleid=|8|9573.

32. Micha R, Peñalvo J, Cudhea F, Imamura F, Rehm C, Mozaffarian D. Association between dietary factors and mortality from heart disease, stroke, and type 2 diabetes in the United States. JAMA 2017:317(9):912-24.

33. Veerman JL, Sacks G, Antonopoulos N, Martin J. The impact of a tax on sugar-sweetened beverages on health and health care costs: A modelling study. PLoS One 20 I 6; | I (4):e0 I 5 | 460. doi: | 0. I 37 |/journal.pone.0 I I | 460.

34. Sánchez-Romero L, Penko J, Coxson P, et al. Projected impact of Mexico's sugar-sweetened beverage tax policy on diabetes and cardiovascular disease: A modeling study. PLoS Med 2016;13(1 I):el002158. doi: 10.1371/journal. pmed. 1002158

35. Schwendicke F, Stolpe M. Taxing sugar-sweetened beverages: Impact on overweight and obesity in Germany. BMC Public Health (Internet) 2017; 17(I):88. Available from: http://www.ncbi.nlm.nih.gov/pubmed/28095809\%0A http://www.pubmedcentral.nih.gov/articlerender.fcgi?artid=PMC5240244\%0A http://bmcpublichealth.biomedcentral.com/articles/ | 0.1 | 86/s | 2889-0 | 6-3938-4.

36. Manyema M, Veerman LJ, Chola L, et al. the potential impact of a $20 \%$ tax on sugar-sweetened beverages on obesity in South African adults: A mathematical model. PLoS One 20 I 4;9(8):el 05287 
37. Manyema M, Veerman LJ, Tugendhaft A, Labadarios D, Hofman KJ. Modelling the potential impact of a sugar-sweetened beverage tax on stroke mortality, costs and health-adjusted life years in South Africa. BMC Public Health (Internet) 20 I6; 16:405. Available from: http://www.ncbi.nlm.nih.gov/pubmed/ 27240422\%5Cnhttp://www.pubmedcentral.nih.gov/articlerender.fcgi?artid= PMC4886444

38. Nakhimovsky SS, Feigl AB, Avila C, O'Sullivan G, Macgregor-Skinner E, Spranca $M$. Taxes on sugar-sweetened beverages to reduce overweight and obesity in middle income countries: A systematic review. PLoS One 20 | 6; I | (9):e0 163358. doi: 10.137|/journal.pone.0163358.

39. Silver LD, Ng SW, Ryan-ibarra S, et al. Changes in prices, sales, consumer spending, and beverage consump tion one year after a tax on sugarsweetened beverages in Berkeley, California, US: A before-and-after study 2017;1-19.

40. Colchero MA, Popkin BM, Rivera JA, Ng SW. Beverage purchases from stores in Mexico under the excise tax on sugar sweetened beverages: Observational study. BMJ 2016;352(h6704): I-9.

41. Colchero M, Rivera-Dommarco J, Popkin B, Ng S. In Mexico, evidence of sustained consumer response two years after implementing a sugarsweetened beverage tax. Health Aff 2017;36(3).

42. Colchero M, Guerrero-López C, Molina M, Rivera J. Beverages sales in Mexico before and after implementation of a sugar sweetened beverage tax. PLoS One 20 | 6; I I (9):e0 I 63463

43. Falbe J, Thompson H, Becker C, Rojas N, McCulloch C, Madsen K. Impact of the Berkeley excise tax on sugar-sweetened beverage consumption. Am J Public Heal 2016; I 06( | 0): 1865-7|.

44. Ismail A. Leaked: Coca-Cola's global sugar tax warfare. News24 2016 Nov.

45. Peyper L. Sugar tax: Negative effects would be "relatively small" - Treasury. Fin24 (Internet) 2017 Feb I; Available from: http://www.fin24.com/Economy/ sugar-tax-negative-effects-would-be-relatively-small-treasury-20 I7020 I

46. Scott-Thomas C. Denmark to scrap decades-old soft drink tax (Internet). Foodnavigator 2013. Available from: http://www.foodnavigator.com/Policy/ Denmark-to-scrap-decades-old-soft-drink-tax. 